\title{
Inflammatory Hyperalgesia: The Role of the Prostaglandin System in the Spinal Cord
}

\author{
Megumi Fujikawa ${ }^{\mathrm{a}, *}$, Takae Ibuki ${ }^{\mathrm{a}}$, Kiyoshi Matsumura ${ }^{\mathrm{b}}$ and Teiji Sawa ${ }^{\mathrm{a}}$ \\ ${ }^{a}$ Department of Anesthesiology, Graduate School of Medical Science, \\ Kyoto Prefectural University of Medicine, Kyoto, Japan \\ ${ }^{\mathrm{b}}$ Department of Biomedical Engineering, Osaka Institute of Technology, Osaka, Japan
}

\begin{abstract}
Hyperalgesia is a symptom often associated with inflammation. The essential role of prostaglandins (PG) in hyperalgesia has long been known since the early $1970 \mathrm{~s}$. Molecular identification of PG receptors and PG-synthesizing enzymes in the late 1980 s/early $1990 \mathrm{~s}$ has greatly advanced the understanding of inflammatory hyperalgesia. In this review, we provide an overview of the PG system in the spinal cord, focusing on its relevance to inflammatory hyperalgesia.
\end{abstract}

Keywords: Inflammation, hyperalgesia, cytokine, prostaglandin, cyclooxygenase-2, spinal cord

\section{INTRODUCTION}

Inflammation, the innate immune response, produces a condition known as hyperalgesia, which is characterized by enhanced pain sensation and reduced pain threshold. Accumulating evidence has shown that prostaglandins (PGs) are involved in hyperalgesia under inflammatory conditions. PGs are lipid mediators derived from unsaturated fatty acids of membrane phospholipids, and play a variety of physiological roles throughout the body [1-3]. Inflammatory hyperalgesia, in particular, involves the PG system in the spinal cord. In this review, we overview the functions and location of the spinal PG system involved in inflammatory hyperalgesia. In the first part, biochemical aspects of PG system are summarized. The second part surveys the literature concerning the hyperalgesic mechanisms of PGs in the spinal cord. The third part reviews how PGs are produced in the spinal cord under inflammatory conditions. In the last part, recent reports on

\footnotetext{
*Correspondence to: Megumi Fujikawa, Department of Anesthesiology, Graduate School of Medical Science, Kyoto Prefectural University of Medicine, 465 Kajii-cho, Kawaramachi - Hirokoji, Kamigyo-ku, Kyoto 602-8566, Japan. Tel.: +81 75 2515633; Fax: +81 75 2515843; E-mail: m-fuji@ koto.kpu-m.ac.jp.
}

novel lipid mediators having anti-nociceptive action are shortly summarized.

\section{BIOCHEMISTRY OF THE PROSTAGLANDIN SYSTEM}

\section{Prostaglandins (PGs)}

All PGs are unsaturated fatty acids with 20 carbon chains. There are three possible precursors for PGs including gamma-linolenic acid, arachidonic acid and eicosapentaenoic acid. Among them, arachidonic acid is the major fatty acid from which PGs having two carbon-carbon double-bonds are biosynthesized. During the $1960 \mathrm{~s}$ and $1970 \mathrm{~s}$, most of the bioactive PGs were identified and named in alphabetical order from PGA to PGI and thromboxane A (TXA). The naturally occurring bioactive ones are PGs $\mathrm{D}_{2}, \mathrm{E}_{2}, \mathrm{~F}_{2 \alpha}$, $\mathrm{I}_{2}$, and $\mathrm{TXA}_{2}$, the numeral " 2 " indicating the number of carbon-carbon double-bonds in the compound (Fig. 1). Enzymes for PG biosynthesis [4] and receptors for their actions [5] are widely distributed in various tissues throughout the body, and, therefore, the biological actions of PGs are extremely diverse. 


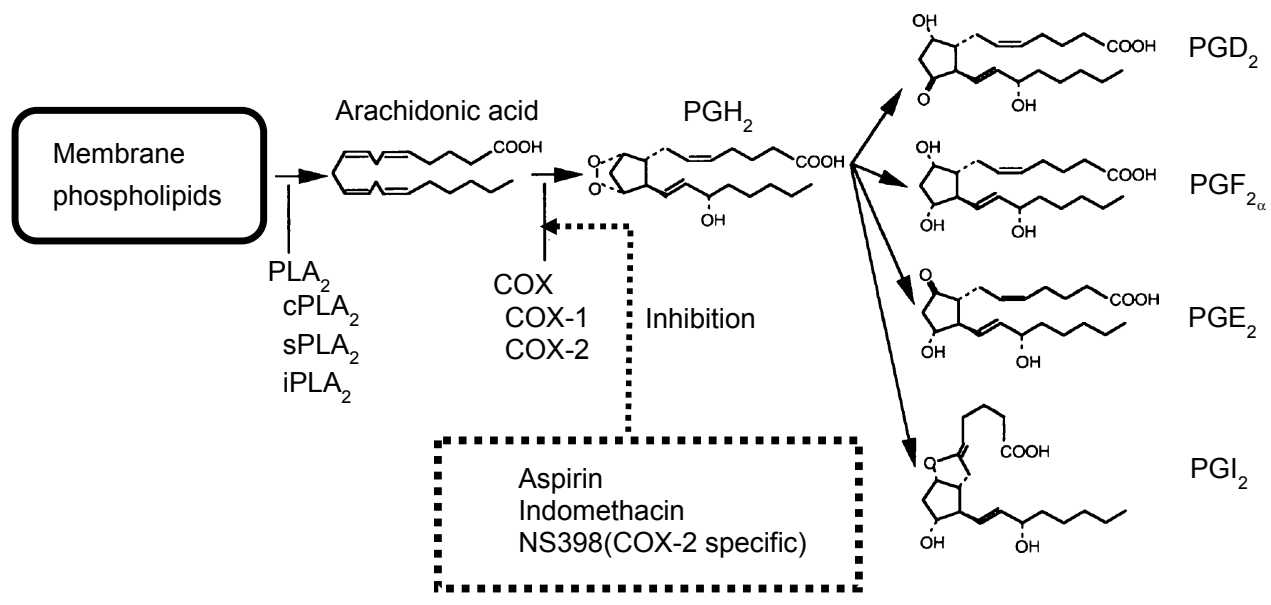

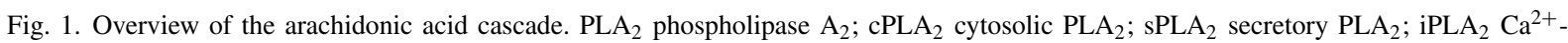
independent PLA 2 ; COX cyclooxygenase.

\section{Enzymes for prostaglandin biosynthesis}

PGs are biosynthesized from phospholipids of the cell membrane through three enzymatic steps (Fig. 1). First, phospholipase $\mathrm{A}_{2}\left(\mathrm{PLA}_{2}\right)$ cleaves arachidonic acid from the membrane phospholipids. Arachidonic acid is then converted to $\mathrm{PGH}_{2}$ by cyclooxygenase $(\mathrm{COX}) . \mathrm{PGH}_{2}$ is converted to bioactive PGs by $\mathrm{PG}$ isomerases. In this enzymatic cascade, $\mathrm{PLA}_{2}$ and $\mathrm{COX}$ are common to all PGs and are considered to play rate-limiting roles in $\mathrm{PG}$ biosynthesis. There are approximately 20 proteins having PLA $_{2}$ activity in mammals [6]. They are classified into three general categories, i.e., cytosolic $\mathrm{PLA}_{2}\left(\mathrm{cPLA}_{2}\right)$, secretory $\mathrm{PLA}_{2}\left(\mathrm{sPLA}_{2}\right)$ and $\mathrm{Ca}^{2+}$-independent PLA $2\left(\mathrm{iPLA}_{2}\right)$. $\mathrm{CPLA}_{2} \mathrm{~S}$ are activated within cells by a nanomolar range of intracellular $\mathrm{Ca}^{2+}$. sPLA $2 \mathrm{~s}$ are secreted from cells and activated by a millimolar range of $\mathrm{Ca}^{2+}$. iPLA $2 \mathrm{~S}$ are cytosolic enzymes and do not require $\mathrm{Ca}^{2+}$ for activation. The second enzyme, COX, a prostaglandin endoperoxide $\mathrm{G} / \mathrm{H}$ synthase, catalyzes two chemical reactions; the first bis-lipoxygenase reaction to synthesize $\mathrm{PGG}_{2}$ from arachidonic acid and, the second peroxidase reaction from $\mathrm{PGG}_{2}$ to $\mathrm{PGH}_{2}$. There are two types of COX, i.e., COX-1 and COX-2. COX-1 is constitutively expressed and seems to be involved in physiological functions under normal conditions. COX-2 is also constitutively expressed in some tissues but promptly induced by various types of stimuli, such as inflammatory cytokines, and is thought to act under both physiological and pathological conditions [7]. PG synthases, which biochemically act as isomerases, have been identified as the third step enzyme including
PGE synthase (PGES) [8], PGI synthase [9], PGD synthase, and PGF synthase. So far 4 proteins possessing PGES activity have been identified including microsomal PGES (mPGES)-1, mPGES-2, cytosolic PGES (cPGES), and the mu class glutathione-S-transferase.

\section{PG membrane receptors}

Based on the results of bioassays, the existence of specific receptors for each $\mathrm{PG}$ was postulated and designated DP, EP, FP, IP, and TP. The EP receptor was further classified into four subtypes (EP1, EP2, EP3, and EP4) based on their preferences for synthetic agonists and antagonists and on the pattern of second-messenger recruitment [5] (Table 1). Molecular cloning of cDNAs for PG receptors was first reported in 1991, revealing the structure of the human thromboxane $\mathrm{A}_{2}$ receptor [10]. Based on the homology with the nucleotide sequence of TX receptor cDNA, cDNAs for other PG receptors have been cloned and expressed in vitro in cell lines for further characterization [11]. The receptor proteins are all coupled to $\mathrm{G}$ proteins and have seven transmembrane domains, a common feature of G-protein-coupled receptors. PG signals at the receptor sites are, thus, converted to second messenger molecules, including cAMP, $\mathrm{Ca}^{2+}$ and inositol triphosphate $[3,12]$.

\section{ROLE OF THE SPINAL PG SYSTEM IN NOCICEPTION}

Nonsteroidal anti-inflammatory drugs (NSAIDs), which are potent and specific inhibitors of COX and 
Table 1

Classification and nomenclature of PG receptors

\begin{tabular}{|c|c|c|c|c|c|}
\hline $\begin{array}{l}\text { Receptor } \\
\text { type }\end{array}$ & $\begin{array}{l}\text { Endogenous } \\
\text { ligand }\end{array}$ & Subtype & G-proteins & $\begin{array}{l}\text { Second } \\
\text { messengers }\end{array}$ & $\begin{array}{l}\text { Histologica } \\
\text { evidence }\end{array}$ \\
\hline TP & $\mathrm{TXA}_{2} / \mathrm{PGH}_{2}$ & & Gs, Gq, Gi & Pl turn over $\uparrow$ & DRG, PNE \\
\hline \multirow[t]{5}{*}{ EP } & $\mathrm{PGE}_{2}$ & EP1 & ? & $\mathrm{Ca}^{2+} \uparrow$ & DRG \\
\hline & & EP2 & Gs & cAMP $\uparrow$ & \\
\hline & & EP3 & $\mathrm{Gi}$, Gs & cAMP $\downarrow \uparrow$ & DRG, DH \\
\hline & & & $\mathrm{Gq}$ & Pl turn over $\uparrow$ & \\
\hline & & EP4 & Gs & $\mathrm{cAMP} \uparrow$ & DRG \\
\hline FP & $\mathrm{PGF}_{2 \alpha}$ & & $\mathrm{Gq}$ & Pl turn over $\uparrow$ & \\
\hline \multirow[t]{2}{*}{ IP } & $\mathrm{PGI}_{2}$ & & Gs & cAMP $\uparrow$ & DRG, DH \\
\hline & & & $\mathrm{Gq}$ & Pl turn over $\uparrow$ & \\
\hline DP & $\mathrm{PGD}_{2}$ & & Gs & cAMP $\uparrow$ & \\
\hline CRTH2 & $\mathrm{PGD}_{2}$ & & $\mathrm{Gi}$ & cAMP $\downarrow$ & \\
\hline
\end{tabular}

PI: inositol-3-phosphate, ?: not identified, DRG: dorsal root ganglia, PNE: peripheral nerve endings, DH: dorsal horn.

inhibiting the production of proinflammatory chemical mediators, are also potent analgesics [13-15]. This fact strongly suggests that endogenous PGs enhance nociceptive function. Indeed, $\mathrm{PGE}_{2}, \mathrm{PGI}_{2}$, $\mathrm{PGF}_{2 \alpha}$ and $\mathrm{PGD}_{2}$ induce hyperalgesia or allodynia [16] when injected centrally or peripherally. Among these $\mathrm{PGs}, \mathrm{PGE}_{2}$ and $\mathrm{PGI}_{2}$ are best studied in various models of inflammatory hyperalgesia. Although there seem to be multiple sites within the nervous system where PGs act to modulate pain signal transmission, accumulating evidence indicates that the primary sensory neurons are the major targets for the hyperalgesic actions of PGs. The primary sensory neurons are bipolar in shape, sending one process to peripheral tissue and the other to the dorsal horn of the spinal cord with the cell bodies located in the dorsal root ganglia. PGs are likely to act on both terminals of these neuronal processes to induce hyperalgesia.

\section{Location of $P G$ receptors in the spinal cord}

Studies in mice showed an abundant expression of mRNAs for EP and IP receptors in the neurons of sensory ganglia $[17,18]$. An immunohistochemical study of EP3 revealed its expression in the neurons of sensory ganglia in rats [19]. These results indicate that $\mathrm{PG}$ receptors are produced in the primary sensory neurons.

Distribution of PG receptors was also investigated by binding of radio-labeled receptor ligands to frozen sections [20]. This approach can demonstrate the sites of receptor functioning rather than the sites of receptor production. An autoradiographical study using ${ }^{3} \mathrm{H}$ labeled $\mathrm{PGE}_{2}$ or ${ }^{3} \mathrm{H}$-labeled iloprost, a stable $\mathrm{PGI}_{2}$ analog, showed that a high density of iloprost binding sites and $\mathrm{PGE}_{2}$ binding sites was present in the superficial layers of the dorsal horn (Fig. 2a, c) and the spinal trigeminal nucleus. An immunohistochemical study also localized EP3-like immunoreactivity in the superficial layers of rat dorsal horn [19]. The dorsal horn and the spinal trigeminal nucleus receive somatosensory primary afferent inputs, the former from the dorsal root ganglia and the latter from the trigeminal ganglia. Importantly the superficial layers of the dorsal horn and the spinal trigeminal nucleus receive nociceptive and thermosensitive inputs via unmyelinated fibers (C-fiber) and fine myelinated fibers (A $\delta$-fiber).

As all the above mentioned regions receive primary sensory afferents, there arose a possibility that these PG receptors are located in the central terminals of the primary sensory afferent but not in the postsynaptic neurons in the dorsal horn or in the medulla. This possibility was examined in rats in which some of the dorsal roots were unilaterally sectioned between the dorsal root ganglia and the spinal cord. Eight days after the dorsal roots had been sectioned, the binding sites for $\mathrm{PGE}_{2}$ and iloprost were significantly decreased, almost disappeared, ipsilateral to the lesion [20] (Fig. 2b, d). These results clearly demonstrate that the receptors for PGs are biosynthesized in the sensory ganglia and function after being transported to the central sensory terminals in the spinal cord and medulla oblongata. In contrast, there is no histological study that localizes EP or IP receptors in the peripheral terminals of sensory neurons. However, the physiological studies described below clearly indicate the presence of EP and IP receptors in the peripheral terminals of sensory neurons. 

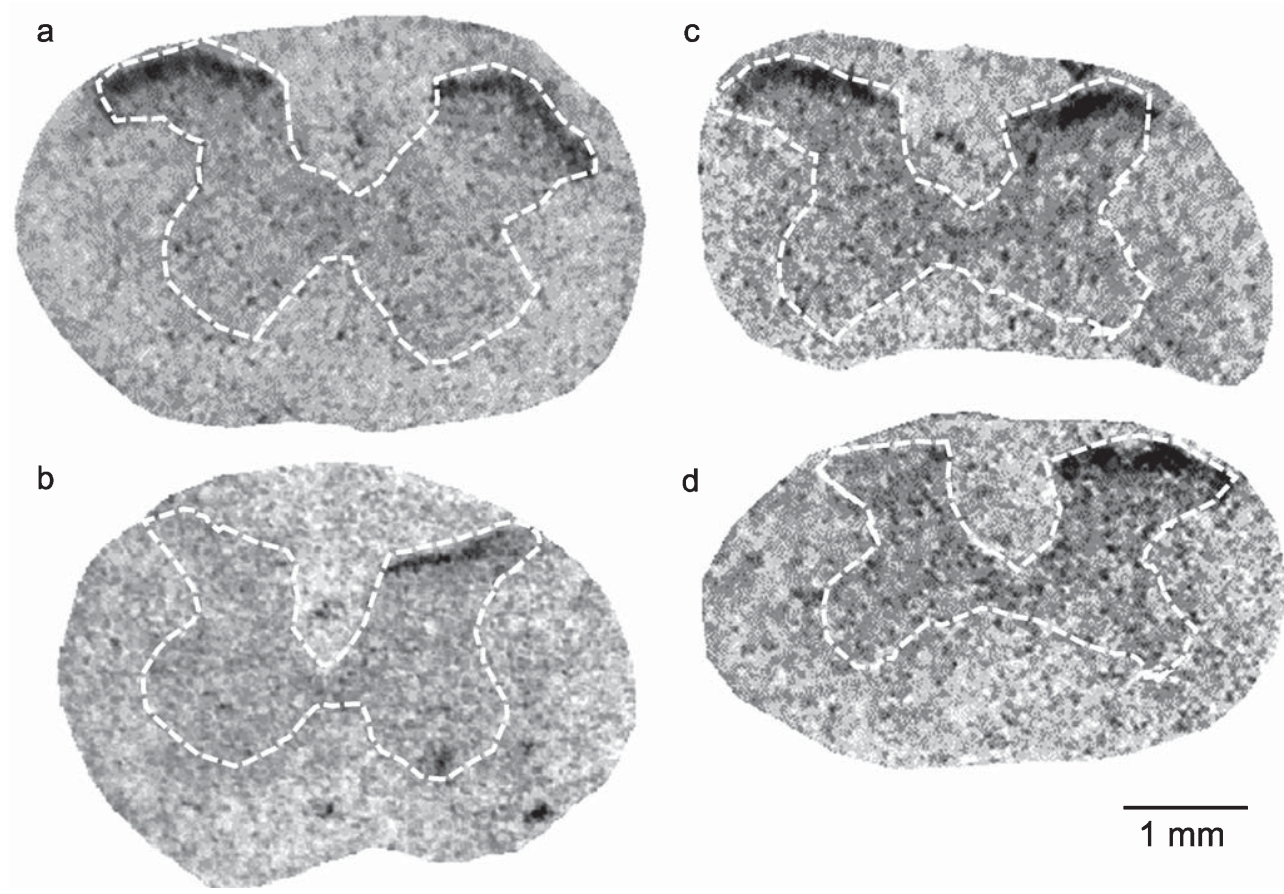

Fig. 2. Receptor autoradiography of PG receptors in the rat spinal cord. (a) ${ }^{3} \mathrm{H}-\mathrm{PGE}_{2}$ binding sites (b) ${ }^{3} \mathrm{H}-\mathrm{PGE} 2$ binding sites 8 days after the dorsal root had been sectioned unilaterally (c) ${ }^{3} \mathrm{H}$-iloprost (a stable analogue of $\mathrm{PGI}_{2}$ ) binding sites (d) ${ }^{3} \mathrm{H}$-iloprost binding sites 8 days after the dorsal root had been sectioned unilaterally. Dotted lines delineate the gray matter.

Action of PGs in the peripheral terminals of the primary nociceptive neurons

PGs when injected into peripheral tissues evoke hyperalgesia. This was first demonstrated in humans in 1972 [21] and was confirmed by a large number of studies using behavioral pain models in experimental animals, such as the paw-withdrawal reflex to a mechanical or heat stimulus. The results are largely consistent with $\mathrm{PGE}_{2}$ and $\mathrm{PGI}_{2}$ being the most potent PGs in augmenting behavioral pain when injected into peripheral tissues [22, 23] and that these PGs themselves do not evoke pain but instead lower the threshold for pain evoked by other stimuli, a phenomenon called sensitization.

Hyperalgesia is often associated with peripheral inflammation. Application of NSAIDs, inhibitors of cyclooxygenase, to the inflamed tissue suppresses hyperalgesia. Thus, endogenous PGs seem to work as a mediator of hyperalgesia during inflammation. Consistent with these findings from behavioral studies, neurophysiological experiments also showed that application of $\mathrm{PGE}_{2}, \mathrm{PGI}_{2}$ or an analog of $\mathrm{PGI}_{2}$ to peripheral tissues increased the number of afferent nociceptive fiber action potentials [24-27]. These results clearly indicate that the peripheral terminals of the primary nociceptive neurons are the sites of hyperalgesic action of $\mathrm{PGE}_{2}$ and $\mathrm{PGI}_{2}$. The ionic mechanism by which PGs lower the pain threshold remains to be clarified in vivo. This is mainly due to the difficulty in conducting electrophysiological experiments in the peripheral terminals of primary sensory neurons. Instead, electrophysiological studies employing cultured sensory neurons in vitro have provided important information on the mechanism of PG-induced sensitization. A long-lasting hyperpolarization, which follows an action potential, was present in a subpopulation of primary sensory neurons. This hyperpolarization was driven by a $\mathrm{Ca}^{2+}$-dependent $\mathrm{K}^{+}$ current and thought to reduce the excitability of the neurons. $\mathrm{PGE}_{2}$ suppressed this current and therefore, increased the excitability of the neurons [28, 29]. This idea is in agreement with the in vivo observation that $\mathrm{PGE}_{2}$ itself does not induce pain but instead lowers the threshold for pain elicited by other stimuli.

Another possible mechanism has also been proposed. A subpopulation of primary sensory neurons in culture was shown to possess a tetrodotoxin-resistant 
$\mathrm{Na}^{+}$current. $\mathrm{PGE}_{2}$ augmented this current in a cAMP-dependent manner, thus increasing neuronal excitability [30, 31].

Another intriguing hypothesis involves the noxious heat receptor TRPV1, which is a cation channel activated by capsaicin, low $\mathrm{pH}$, and noxious heat above $42^{\circ} \mathrm{C}$. TRPV 1 is highly expressed in small- to mediumsized primary sensory neurons in both the central and peripheral terminals of their axons. Activation of TRPV1 induces cation inflow and consequently, elevates the excitability of neurons [32]. TRPV1expressing neurons are therefore, considered to be involved in nociception. Moriyama et al. [33] demonstrated that $\mathrm{PGE}_{2}$ and $\mathrm{PGI}_{2}$ phosphorylate TRPV1 in a cAMP-dependent manner and lowers the temperature threshold for activation to normal body temperature. Thus, in inflamed tissues, the excitability of TRPV1expressing sensory terminals should be elevated by $\mathrm{PGE}_{2}$ and $\mathrm{PGI}_{2}$, resulting in hyperalgesia.

\section{Action of PGs in the central terminals of primary sensory neurons}

As in the case of peripheral application of PGs, intrathecal infusions of PGs also modulate (mostly facilitate) nociception. $\mathrm{PGE}_{2}, \mathrm{PGD}_{2}$, and $\mathrm{PGF}_{2 \alpha}$ have been reported to induce hyperalgesia when infused intrathecally [34-37]. Effects of intrathecal injection of PGs are classified into two categories: allodynia and hyperalgesia. Allodynia is a state of discomfort and pain evoked by innocuous stimuli such as a gentle touch or brushing, whereas hyperalgesia is a state of lowered threshold for pain to a eventually noxious stimulus. Minami et al. [34, 35] showed that $\mathrm{PGE}_{2}$ and $\mathrm{PGF}_{2 \alpha}$ induced allodynia and that $\mathrm{PGE}_{2}$ also induced hyperalgesia. Using subtype-specific agonists for $\mathrm{PGE}_{2}$ receptors, they showed that $\mathrm{PGE}_{2}$ induced allodynia through the EP1 receptor whereas hyperalgesia occurred through the EP3 receptor [34].

Again, intrathecal injection of NSAIDs in rats suppressed the hyperalgesia elicited either by injection of formalin in peripheral tissue [38] or by subcutaneous injection of carrageenan in the hind paw [39]. The central terminals of the primary sensory neurons principally release glutamate to transmit the pain signals. Neuropeptides, such as substance P (SP) and calcitonin gene-related peptide (CGRP) are also released and considered to be involved in the modulation of pain signals. Using an intrathecal microdialysis probe, Malmberg and Yaksh [40] showed that intradermal injection of formaldehyde into a rat hind paw, a treatment which provokes biphasic behavioral pain, increased the levels of excitatory amino acids and $\mathrm{PGE}_{2}$ in the cerebrospinal fluid of the lumbar cord. Intrathecal as well as intraperitoneal administration of an NSAID lowered the levels of $\mathrm{PGE}_{2}$, excitatory amino acids, and behavioral pain.

Similarly, using carrageenan/kaoline-induced knee joint inflammation as an experimental model, Yang et al. [41] demonstrated increases in the levels of excitatory amino acids, $\mathrm{PGE}_{2}$, and behavioral pain. Intrathecal infusion of capsaicin evoked behavioral pain and amino acid release, and co-administration of $\mathrm{PGE}_{2}$ enhanced these responses [42].

The effects of PGs on neuropeptide release were mainly studied in cell culture systems. $\mathrm{PGE}_{2}$ as well as $\mathrm{PGI}_{2}$ and carbacyclin, a stable $\mathrm{PGI}_{2}$ analog, enhanced the release of SP and CGRP by bradykinin from rat sensory neurons in culture [43, 44]. These results imply that PGs also act on the central terminals of sensory neurons to enhance pain transmission by increasing the release of excitatory amino acids and/or neuropeptides.

\section{Postsynaptic action of $P G E_{2}$ in the spinal cord}

$\mathrm{PGE}_{2}$ also acts on the spinal cord neurons postsynaptically. Glycine is an inhibitory neurotransmitter in the spinal cord pain pathway. Alpha3 glycine receptors are located in lamina II neurons of spinal dorsal horn. Electrophysiological study showed that $\mathrm{PGE}_{2}$ acts on lamina II neurons and reduces the amplitude of glycine-induced inhibitory postsynaptic current [45]. This should result in the enhancement of neuronal excitability of the pain pathway. The action of $\mathrm{PGE}_{2}$ on the glycine receptor is mediated by EP2 $\mathrm{PGE}_{2}$ receptor and subsequent cAMP-protein kinase A signaling [46]. Consistently with the electrophysiological results, behavioral study using gene-deleted mice showed that EP2 $\mathrm{PGE}_{2}$ receptor and alpha3 glycine receptor are involved in the inflammatory hyperalgesia [46]. Thus, $\mathrm{PGE}_{2}$ acts both pre- and post-synaptic sites of the dorsal horn neurons to enhance pain signal transmission.

\section{Inflammatory hyperalgesia in $P G$ receptor-deficient mice}

Inflammatory hyperalgesia have been studied in mice genetically lacking PG receptors (Table 2). Although the models of inflammation were limited, these studies clearly demonstrated the involvement of EP and IP receptors in inflammatory hyperalgesia. It should be also noted that hyperalgesia was enhanced in mice lacking some of the PG receptors. 
Table 2

Inflammatory hyperalgesia in PG receptor-deficient mice

\begin{tabular}{|c|c|c|c|c|}
\hline Genotype & $\begin{array}{l}\text { Inflammatory model } \\
\text { (route of application) }\end{array}$ & $\begin{array}{l}\text { Type of } \\
\text { hyperalgesia }\end{array}$ & $\begin{array}{l}\text { Changes in } \\
(-/-) \text { mice }\end{array}$ & Ref \\
\hline \multirow[t]{3}{*}{$\mathrm{EP} 1(-/-)$} & $\mathrm{PGE}_{2}$ (s.c.) & Thermal & $\downarrow$ & [33] \\
\hline & $\mathrm{PGE}_{2}$ (i.t.) & Mechanical allodynia & $\downarrow$ & [68] \\
\hline & Mustard oil (skin) & Thermal & $\downarrow$ & [33] \\
\hline \multirow{4}{*}{$\mathrm{EP} 2(-/-)$} & $\mathrm{PGE}_{2}$ (i.t.) & Thermal/mechanical & $\downarrow$ & [46] \\
\hline & $\mathrm{PGE}_{2}$ (s.c.) & Mechanical & $\downarrow$ & [46] \\
\hline & Zymosan A (s.c.) & Thermal/mechanical & $\downarrow$ & [46] \\
\hline & Formalin (s.c.) & Flinching & $\uparrow$ & [50] \\
\hline \multirow[t]{2}{*}{$\mathrm{EP} 3(-/-)$} & Formalin (s.c.) & Licking & $\downarrow$ & {$[50]$} \\
\hline & LPS (i.p.) & Writhing to acetic acid (i.p.) & $\downarrow$ & [69] \\
\hline \multirow[t]{2}{*}{$\operatorname{IP}(-/-)$} & Acetic acid (i.p.) & writhing & $\downarrow$ & [70] \\
\hline & $\mathrm{PGI}_{2}$ (s.c.) & Thermal & $\downarrow$ & [33] \\
\hline DP1 & Formalin (s.c.) & Flinching & $\uparrow$ & [33] \\
\hline
\end{tabular}

$\downarrow:$ reduced, $\uparrow:$ enhanced, s.c.: subcutaneous, i.t.: intrathecal, i.p.: intraperitoneal.

This fact suggests that some PG receptors may have anti-nociceptive function.

\section{PG SYNTHESIS IN THE SPINAL CORD UNDER INFLAMMATORY CONDITIONS}

Although the hyperalgesic actions of PGs were reported in the early $1970 \mathrm{~s}$, it continued to be unclear for a long time how PGs are produced in the spinal cord under inflammatory conditions. The discovery of COX-2, the inducible type of COX, opened the way to answer this question. A number of studies in both human and experimental animals have shown that COX-2 inhibitors are quite potent in suppressing hyperalgesia under inflammatory conditions [47, 48]. COX-2-deficient mice showed reduced hyperalgesia in acute and chronic inflammation models $[49,50]$. These facts strongly suggest that $\mathrm{PGE}_{2}$ and/or $\mathrm{PGI}_{2}$ produced by COX-2 act on the peripheral or central terminals of nociceptive neurons, which seems to be the primary targets of hyperalgesic PGs.

We and other groups have succeeded in identifying COX-2-expressing cells in the spinal cord under different inflammatory conditions. These conditions include subcutaneous injection of carrageenan, burn injury and subcutaneous injection of complete Freund's adjuvant (CFA), the former two being models for acute peripheral inflammation, and the latter being a model for chronic peripheral inflammation. The results obtained in these three models are summarized below.

\section{Carrageenan model}

Carrageenan-induced inflammation evoked thermal hyperalgesia. This hyperalgesia was suppressed by systemic or intrathecal injection of NS398, a COX-2specific inhibitor [39]. Carrageenan injection induced expression of COX-2-like immunoreactivity in vascular endothelial cells throughout the central nervous system including the spinal cord (Fig. 3a). This response became evident by $3 \mathrm{~h}$, and was most prominent at $6 \mathrm{~h}$ after carrageenan injection. The COX-2 induction was associated with an elevation of $\mathrm{PGE}_{2}$ in the cerebrospinal fluid, being evident at $3 \mathrm{~h}$, larger at $6 \mathrm{~h}$, and alleviated by a COX-2 selective inhibitor [39]. Thus, in this model, hyperalgesia seems to be brought about by $\mathrm{PGE}_{2}$, and possibly $\mathrm{PGI}_{2}$, that are produced in and released from endothelial cells in the spinal cord, and sensitize the central terminals of primary nociceptive neurons.

The next question is how peripheral inflammation induced COX-2 in the spinal cord. Our subsequent study indicated the involvement of a cytokine, interleukin-6 (IL-6). Levels of IL-6 but not IL-1 $\beta$ or tumor necrosis factor $\alpha$ were significantly elevated in the circulating blood $3 \mathrm{~h}$ after carrageenan injection. A prior intraperitoneal injection of IL- 6 antiserum attenuated COX-2 expression, $\mathrm{PGE}_{2}$ levels in the cerebrospinal fluid (CSF), and thermal hyperalgesia [51]. IL-6 seemed to directly act on endothelial cells because signal transducer and activator of transcription 3 (STAT3), an intracellular messenger downstream of IL-6 receptor activation, translocated to the nucleus in endothelial cells, which also expressed COX-2. These results suggest that circulating IL- 6 could act as a messenger of inflammatory information from peripheral inflammatory sites to the CNS via the brain endothelial cells. In addition, this study showed that carrageenan injection also induced mPGES-1 (Fig. 3b), which converts $\mathrm{PGH}_{2}$ to $\mathrm{PGE}_{2}$ in endothelial cells, where 

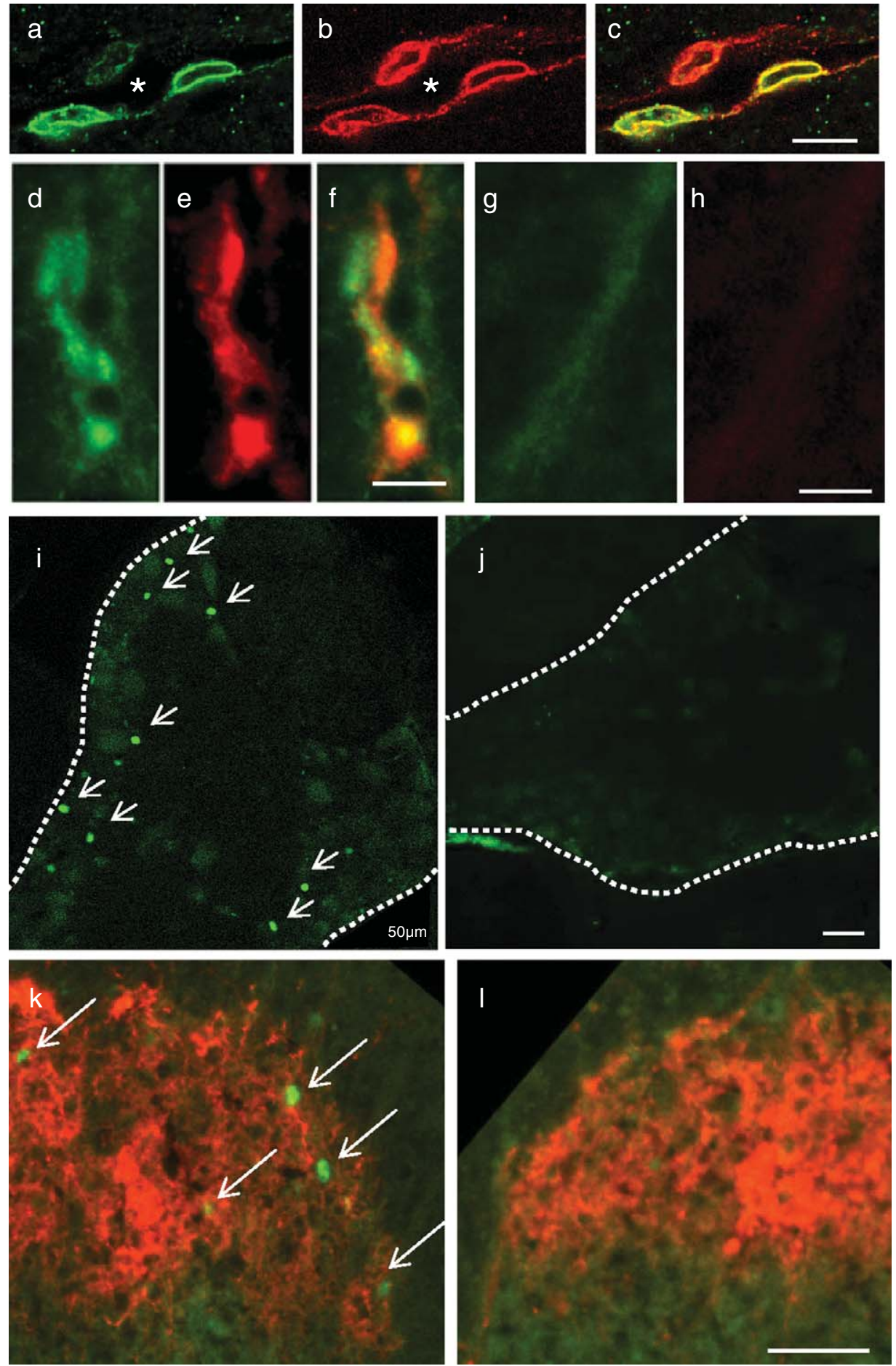

Fig. 3. (a-c) Double immunostaining of COX-2 (a) and mPGES-1 (b) in rat vascular endothelial cells $6 \mathrm{~h}$ after carrageenan injection in the hind paw. Asterisks indicate the lumen of blood vessel. (c) merged view, (d-h) double immunostaining of pNFkB (d, g) and COX-2 (e, h) in the rat spinal cord $3 \mathrm{~h}$ after carrageenan injection (d-f) or saline ( $\mathrm{g}-\mathrm{h}$ ) in the hind paw. (f) merged view, (i-j) pNFkB in the right L4 dorsal root ganglion (i) and left L4 dorsal root ganglion (j) $20 \mathrm{~min}$ after formalin injection to the right hind paw in a mouse. Arrows indicate pNFkB-positive cells. Dotted lines delineate the border of dorsal root ganglion (k-l) double immunostaining of pNFkB (green) and TRPV1 (red) in the right dorsal horn ( $\mathrm{k}$ ) and the left dorsal horn (1) of a rat $3 \mathrm{~h}$ after carrageenan injection in the right hind paw. Arrows indicate pNFkB-positive cells. Scale bars in (c), (f), (h) indicate $10 \mu \mathrm{m}$, and those in (j) and (1) indicate $50 \mu \mathrm{m}$. 
mPGES-1 was colocalized with COX-2 (Fig. 3c). Both COX-2 and mPGES-1 were negative in rats injected saline (data not shown).

\section{Burn injury model}

Burn injury often accompanies hyperalgesia [52, 53]. Thirty six hours after approximately $25 \%$ full thickness burn injury in rats, $\mathrm{PGE}_{2}$ in the CSF was significantly elevated and this elevation was suppressed by a COX-2 specific inhibitor, NS398. In burn-injured rats but not in intact ones, COX-2 and mPGES-1 proteins were detected in vascular endothelial cells throughout the CNS including the spinal cord. COX-2 and mPGES-1 are colocalized in the perinuclear region of the endothelial cells [54]. These enzymes likely elevate the CSF concentration of $\mathrm{PGE}_{2}$, a prostanoid that, in turn, activates $\mathrm{PGE}_{2}$ receptors on the spinal and higher order neurons involved in hyperalgesia following burn injury.

\section{CFA model}

Intraplanter injection of CFA also evokes inflammation and hyperalgesia in rats. This hyperalgesia is dependent on COX-2 in the spinal cord [55-57], as in the case of hyperalgesia by carrageenan. In contrast, however, several studies showed that cells expressing COX-2 in the spinal cord were neurons but not endothelial cells [58-60]. Furthermore, some studies indicated the involvement of IL- $1 \beta$ and TNF- $\alpha$ in the induction of COX-2 [59, 61]. The differences in the type of COX-2 expressing cells and in the type of cytokines involved suggest distinct mechanisms underlying signal transmission from the peripheral inflammatory loci to the CNS between the acute (carrageenan) and chronic (CFA) inflammation models. It is possible that long lasting neuronal activation in chronic inflammation may induce COX-2 in neurons as discussed below.

\section{Possible role of nuclear factor kappa $B$ in inflammatory hyperalgesia}

Nuclear factor kappa B (NFkB) is a transcription factor, activation of which induces a series of proteins involved in inflammation. COX-2 induction is under the control of $\mathrm{NFkB}$ in various cell types. Spinal NFkB activation induced COX-2 upregulation and contributed to inflammatory pain hypersensitivity [62]. We found nuclear localization of phosphorylated $\mathrm{NFkB}$ (pNFkB), an activated form of NFkB, in endothelial cells in the spinal cord $3 \mathrm{~h}$ after carrageenan injection in the hind paw (Fig. 3d). In these endothelial cells, pNFkB was colocalized with COX2 (Fig. 3e, f) suggesting that pNFkB in endothelial cells activates induction of COX-2 cooperatively with STAT3. Both pNFkB and COX-2 were negative in the spinal cord $3 \mathrm{~h}$ after saline injection in the hind paw (Fig. 3g, h).

We also found intense sensory stimuli to the skin resulted in nuclear translocation of $\mathrm{pNFkB}$ in primary sensory neurons [63]. Nuclear translocation of pNFkB occurred in the right L4 dorsal root ganglia (Fig. 3i) but not in the left L4 dorsal root ganglia (Fig. 3j) 20 min after formalin injection in the right hind paw. Furthermore, nuclear translocation of pNFkB was also observed in the dorsal horn neurons, possibly the second order sensory neurons, $3 \mathrm{~h}$ after carrageenan injection in the hind paw (Fig. 3h). The response was restricted to the injection side since contralateral dorsal horn did not show any pNFkB-positive neurons (Fig. 3i). This result suggests that painful stimuli activate NFkB in the primary and second order sensory neurons, and facilitate the induction of inflammationrelated genes. If painful stimuli continue for a certain period under chronic inflammatory states, the activation of $\mathrm{NFkB}$ may induce $\mathrm{COX}-2$ in neurons and contribute to the maintenance of the hyperalgesic state.

\section{LIPID MEDIATORS HAVING ANTI-NOCICEPTIVE ACTION}

Studies in the late $1990 \mathrm{~s}$ to $2000 \mathrm{~s}$ identified a series of lipid mediators having anti-inflammatory and proresolving activities and designated them as lipoxins, resolvins and protectins [64]. Lipoxins are derived from omega- 6 polyunsaturated fatty acid, arachidonic acid, while resolvins and protectins are from omega3 polyunsaturated fatty acid, i.e., eicosapentaenoic acid and docosahexaenoic acid. Recent studies demonstrated that some of these lipid mediators exert potent anti-nociceptive action. Resolvin E1 (RvE1), RvD1 and RvD2 attenuate inflammatory hyperalgesia when applied to the inflamed loci at the dose of $1 \mathrm{ng}$ or less $[65,66]$. RvE1 and RvD2 are also effective when applied intrathecally. The anti-nociceptive mechanism of Rvs seems to involve their inhibitory action on the sensory TRP channels including TRPV1, TRPA1, TRPV3 and TRPV4 [65, 67]. The effective concentrations $\left(\mathrm{IC}_{50}\right)$ are quite low ranging from $0.1 \mathrm{nM}$ to $9 \mathrm{nM}$. The actions of Rvs on the TRP channels are indirect via the G-protein coupled receptors. These results suggest 
that inflammatory hyperalgesia is controlled by the balance between hyperalgesic PGs and anti-nociceptive Rvs.

\section{PERSPECTIVES}

Molecular identification of PG receptors and PGsynthesizing enzymes in the $1990 \mathrm{~s}$ has greatly advanced the understanding of inflammatory hyperalgesia. There are, however, a number of issues to be answered. Among them, it is of special importance to identify the PLA 2 isoform that supplies arachidonic acid to COX-2 to induce inflammatory hyperalgesia. Another issue would be how COX-2 is differentially regulated in endothelial cells and neurons in acute and chronic inflammatory states. Furthermore, recent findings of anti-nociceptive Rvs lead us to reconsider inflammatory hyperalgesia on the basis of its initiation and resolution. It is of importance to understand how the biosynthesis of hyperalgesic PGs and anti-nociceptive Rvs are differentially regulated in the course of inflammation and its resolution.

\section{ACKNOWLEDGMENTS}

We thank Dr. Tony Yaksh for valuable suggestion on the manuscript This work was supported in part by KAKENHI (22590231).

\section{REFERENCES}

[1] Bazan NG, Rodriguez de Turco EB, Allan G. Mediators of injury in neurotrauma: intracellular signal transduction and gene expression. J Neurotrauma. 1995; 12(5): 791.

[2] Shimizu T, Wolfe LS. Arachidonic acid cascade and signal transduction. J Neurochem. 1990; 55(1): 1.

[3] Woodward DF, Jones RL, Narumiya S. International Union of Basic and Clinical Pharmacology. LXXXIII: classification of prostanoid receptors, updating 15 years of progress. Pharmacol Rev. 2011; 63(3): 471

[4] Smith WL, Marnett LJ, DeWitt DL. Prostaglandin and thromboxane biosynthesis. Pharmacol Ther. 1991; 49(3): 153

[5] Coleman RA, Smith WL, Narumiya S. International Union of Pharmacology classification of prostanoid receptors: properties, distribution, and structure of the receptors and their subtypes. Pharmacol Rev. 1994; 46(2): 205.

[6] Murakami M, Taketomi Y, Miki Y, Sato H, Hirabayashi T, Yamamoto K. Recent progress in phospholipase A research: from cells to animals to humans. Progress in lipid research. 2011; 50(2): 152.

[7] Goppelt-Struebe M. Regulation of prostaglandin endoperoxide synthase (cyclooxygenase) isozyme expression. Prostaglandins Leukot Essent Fatty Acids. 1995; 52(4): 213.

[8] Jakobsson PJ, Thoren S, Morgenstern R, Samuelsson B. Identification of human prostaglandin $\mathrm{E}$ synthase: a microsomal, glutathione-dependent, inducible enzyme, constituting a potential novel drug target. Proc Natl Acad Sci U S A. 1999; 96(13): 7220 .

[9] Hara S, Miyata A, Yokoyama C, Inoue H, Brugger R, Lottspeich $\mathrm{F}$, et al. Isolation and molecular cloning of prostacyclin synthase from bovine endothelial cells. The Journal of biological chemistry. 1994; 269(31): 19897.

[10] Hirata M, Hayashi Y, Ushikubi F, Yokota Y, Kageyama R, Nakanishi S, et al. Cloning and expression of cDNA for a human thromboxane A2 receptor. Nature. 1991; 349(6310): 617.

[11] Ushikubi F, Hirata M, Narumiya S. Molecular biology of prostanoid receptors; an overview. J Lipid Mediat Cell Signal. 1995; 12(2-3): 343.

[12] Hirai H, Tanaka K, Yoshie O, Ogawa K, Kenmotsu K, Takamori Y, et al. Prostaglandin D2 selectively induces chemotaxis in Thelper type 2 cells, eosinophils, and basophils via seven-transmembrane receptor CRTH2. The Journal of experimental medicine. 2001; 193(2): 255.

[13] Ferreira SH, Prostaglandins, aspirin-like drugs and analgesia. Nat New Biol. 1972; 240(102): 200.

[14] Ferreira SH, Moncada S, Vane JR. Prostaglandins and the mechanism of analgesia produced by aspirin-like drugs. Br J Pharmacol. 1973; 49(1): 86.

[15] Vane JR. Inhibition of prostaglandin synthesis as a mechanism of action for aspirin-like drugs. Nat New Biol. 1971; 231(25): 232

[16] Ito S, Okuda-Ashitaka E, Minami T. Central and peripheral roles of prostaglandins in pain and their interactions with novel neuropeptides nociceptin and nocistatin. Neurosci Res. 2001; 41(4): 299.

[17] Oida H, Namba T, Sugimoto Y, Ushikubi F, Ohishi H, Ichikawa $\mathrm{A}$, et al. In situ hybridization studies of prostacyclin receptor mRNA expression in various mouse organs. $\mathrm{Br}$ J Pharmacol. 1995; 116(7): 2828.

[18] Sugimoto Y, Shigemoto R, Namba T, Negishi M, Mizuno N, Narumiya S, et al. Distribution of the messenger RNA for the prostaglandin $\mathrm{E}$ receptor subtype EP3 in the mouse nervous system. Neuroscience. 1994; 62(3): 919.

[19] Nakamura K, Kaneko T, Yamashita Y, Hasegawa H, Katoh H, Negishi M. Immunohistochemical localization of prostaglandin EP3 receptor in the rat nervous system. The Journal of comparative neurology. 2000; 421(4): 543.

[20] Matsumura K, Watanabe Y, Onoe H, Watanabe Y. Prostacyclin receptor in the brain and central terminals of the primary sensory neurons: an autoradiographic study using a stable prostacyclin analogue $[3 \mathrm{H}]$ iloprost. Neuroscience. 1995; 65(2): 493.

[21] Collier JG, Karim SM, Robinson B, Somers K. Proceedings: action of prostaglandins A2, B-1, E2 and F2 alpha on superficial hand veins of man. Br J Pharmacol. 1972; 44(2): 374P.

[22] Ferreira SH, Nakamura M, de Abreu Castro MS. The hyperalgesic effects of prostacyclin and prostaglandin E2. Prostaglandins. 1978; 16(1): 31.

[23] Taiwo YO, Levine JD. Effects of cyclooxygenase products of arachidonic acid metabolism on cutaneous nociceptive threshold in the rat. Brain Res. 1990; 537(1-2): 372.

[24] Birrell GJ, McQueen DS. The effects of capsaicin, bradykinin, PGE2 and cicaprost on the discharge of articular sensory receptors in vitro. Brain Res. 1993; 611(1): 103.

[25] Birrell GJ, McQueen DS, Iggo A, Coleman RA, Grubb BD. PGI2-induced activation and sensitization of articular mechanonociceptors. Neurosci Lett. 1991; 124(1): 5.

[26] Chahl LA, Iggo A. The effects of bradykinin and prostaglandin $\mathrm{E} 1$ on rat cutaneous afferent nerve activity. $\mathrm{Br}$ J Pharmacol. 1977; 59(2): 343. 
[27] Mense S. Sensitization of group IV muscle receptors to bradykinin by 5-hydroxytryptamine and prostaglandin E2. Brain Res. 1981; 225(1): 95.

[28] Gold MS, Shuster MJ, Levine JD. Role of a Ca(2+)-dependent slow afterhyperpolarization in prostaglandin E2-induced sensitization of cultured rat sensory neurons. Neurosci Lett. 1996; 205(3): 161.

[29] Undem BJ, Weinreich D. Electrophysiological properties and chemosensitivity of guinea pig nodose ganglion neurons in vitro. J Auton Nerv Syst. 1993; 44(1): 17.

[30] England S, Bevan S, Docherty RJ. PGE2 modulates the tetrodotoxin-resistant sodium current in neonatal rat dorsal root ganglion neurones via the cyclic AMP-protein kinase A cascade. J Physiol. 1996; 495(Pt 2): 429.

[31] Gold MS, Reichling DB, Shuster MJ, Levine JD. Hyperalgesic agents increase a tetrodotoxin-resistant $\mathrm{Na}+$ current in nociceptors. Proc Natl Acad Sci U S A. 1996; 93(3): 1108 .

[32] Caterina MJ, Schumacher MA, Tominaga M, Rosen TA, Levine JD, Julius D. The capsaicin receptor: a heat-activated ion channel in the pain pathway. Nature. 1997; 389(6653): 816.

[33] Moriyama T, Higashi T, Togashi K, Iida T, Segi E, Sugimoto Y, et al. Sensitization of TRPV1 by EP1 and IP reveals peripheral nociceptive mechanism of prostaglandins. Mol Pain. 2005; 1: 3.

[34] Minami T, Nishihara I, Uda R, Ito S, Hyodo M, Hayaishi O. Characterization of EP-receptor subtypes involved in allodynia and hyperalgesia induced by intrathecal administration of prostaglandin E2 to mice. Br J Pharmacol. 1994; 112(3): 735.

[35] Minami T, Uda R, Horiguchi S, Ito S, Hyodo M, Hayaishi O. Allodynia evoked by intrathecal administration of prostaglandin F2 alpha to conscious mice. Pain. 1992; 50(2): 223.

[36] Taiwo YO, Levine JD. Prostaglandins inhibit endogenous pain control mechanisms by blocking transmission at spinal noradrenergic synapses. J Neurosci. 1988; 8(4): 1346.

[37] Uda R, Horiguchi S, Ito S, Hyodo M, Hayaishi O. Nociceptive effects induced by intrathecal administration of prostaglandin D2, E2, or F2 alpha to conscious mice. Brain Res. 1990; 510(1): 26.

[38] Malmberg AB, Yaksh TL. Antinociceptive actions of spinal nonsteroidal anti-inflammatory agents on the formalin test in the rat. J Pharmacol Exp Ther. 1992; 263(1): 136.

[39] Ibuki T, Matsumura K, Yamazaki Y, Nozaki T, Tanaka Y, Kobayashi S. Cyclooxygenase-2 is induced in the endothelial cells throughout the central nervous system during carrageenan-induced hind paw inflammation its possible role in hyperalgesia. J Neurochem. 2003; 86(2): 318.

[40] Malmberg AB, Yaksh TL. Cyclooxygenase inhibition and the spinal release of prostaglandin E2 and amino acids evoked by paw formalin injection: a microdialysis study in unanesthetized rats. J Neurosci. 1995; 15(4): 2768.

[41] Yang LC, Marsala M, Yaksh TL. Characterization of time course of spinal amino acids, citrulline and PGE2 release after carrageenan/kaolin-induced knee joint inflammation: a chronic microdialysis study. Pain. 1996; 67(2-3): 345

[42] Malmberg AB, Yaksh TL. Capsaicin-evoked prostaglandin E2 release in spinal cord slices: relative effect of cyclooxygenase inhibitors. Eur J Pharmacol. 1994; 271(2-3): 293.

[43] Hingtgen CM, Vasko MR. Prostacyclin enhances the evokedrelease of substance $\mathrm{P}$ and calcitonin gene-related peptide from rat sensory neurons. Brain Res. 1994; 655(1-2): 51.

[44] Vasko MR, Campbell WB, Waite KJ. Prostaglandin E2 enhances bradykinin-stimulated release of neuropeptides from rat sensory neurons in culture. J Neurosci. 1994; 14(8): 4987.

[45] Harvey RJ, Depner UB, Wassle H, Ahmadi S, Heindl C, Reinold H, et al. GlyR alpha3: an essential target for spinal PGE2-mediated inflammatory pain sensitization. Science. 2004; 304(5672): 884

[46] Reinold H, Ahmadi S, Depner UB, Layh B, Heindl C, Hamza $\mathrm{M}$, et al. Spinal inflammatory hyperalgesia is mediated by prostaglandin E receptors of the EP2 subtype. The Journal of clinical investigation. 2005; 115(3): 673.

[47] Svensson CI, Yaksh TL. The spinal phospholipasecyclooxygenase-prostanoid cascade in nociceptive processing. Annual review of pharmacology and toxicology. 2002; 42: 553.

[48] Tindall E. Celecoxib for the treatment of pain and inflammation: the preclinical and clinical results. The Journal of the American Osteopathic Association. 1999; 99(11 Suppl): S13.

[49] Chillingworth NL, Morham SG, Donaldson LF. Sex differences in inflammation and inflammatory pain in cyclooxygenase-deficient mice. American Journal of Physiology Regulatory, Integrative and Comparative Physiology. 2006; 291(2): R327.

[50] Popp L, Haussler A, Olliges A, Nusing R, Narumiya S, Geisslinger $\mathrm{G}$, et al. Comparison of nociceptive behavior in prostaglandin E, F, D, prostacyclin and thromboxane receptor knockout mice. Eur J Pain. 2009; 13(7): 691.

[51] Oka Y, Ibuki T, Matsumura K, Namba M, Yamazaki Y, Poole $\mathrm{S}$, et al. Interleukin-6 is a candidate molecule that transmits inflammatory information to the CNS. Neuroscience. 2007; 145(2): 530.

[52] Coderre TJ, Melzack R. Increased pain sensitivity following heat injury involves a central mechanism. Behavioural brain research. 1985; 15(3): 259.

[53] Latarjet J, Choinere M. Pain in burn patients. Burns: Journal of the International Society for Burn Injuries. 1995; 21(5): 344.

[54] Ozaki-Okayama Y, Matsumura K, Ibuki T, Ueda M, Yamazaki Y, Tanaka Y, et al. Burn injury enhances brain prostaglandin E2 production through induction of cyclooxygenase-2 and microsomal prostaglandin $\mathrm{E}$ synthase in cerebral vascular endothelial cells in rats. Crit Care Med. 2004; 32(3): 795.

[55] Bingham S, Beswick PJ, Bountra C, Brown T, Campbell IB, Chessell IP, et al. The cyclooxygenase-2 inhibitor GW406381X [2-(4-ethoxyphenyl)-3-[4-(methylsulfonyl) phenyl]-pyrazolo[1,5-b]pyridazine] is effective in animal models of neuropathic pain and central sensitization. J Pharmacol Exp Ther. 2005; 312(3): 1161.

[56] Hay CH, Trevethick MA, Wheeldon A, Bowers JS, de Belleroche JS. The potential role of spinal cord cyclooxygenase-2 in the development of Freund's complete adjuvant-induced changes in hyperalgesia and allodynia. Neuroscience. 1997; 78(3): 843.

[57] Seybold VS, Jia YP, Abrahams LG. Cyclo-oxygenase-2 contributes to central sensitization in rats with peripheral inflammation. Pain. 2003; 105(1-2): 47.

[58] Cheng HT, Suzuki M, Hegarty DM, Xu Q, Weyerbacher AR, South SM, et al. Inflammatory pain-induced signaling events following a conditional deletion of the N-methyl-Daspartate receptor in spinal cord dorsal horn. Neuroscience. 2008; 155(3): 948.

[59] Samad TA, Moore KA, Sapirstein A, Billet S, Allchorne A, Poole S, et al. Interleukin-1beta-mediated induction of Cox-2 in the CNS contributes to inflammatory pain hypersensitivity. Nature. 2001; 410(6827): 471. 
[60] Yamada S, Kawate T, Sakamoto H, Aoki K, Hamada Y, Atsumi S. Cyclo-oxygenase-2-immunoreactive neurons in the lumbar dorsal horn in a chicken acute inflammation model. Anatomical science international. 2006; 81(3): 164.

[61] Narita M, Shimamura M, Imai S, Kubota C, Yajima Y, Takagi $\mathrm{T}$, et al. Role of interleukin-1beta and tumor necrosis factoralpha-dependent expression of cyclooxygenase-2 mRNA in thermal hyperalgesia induced by chronic inflammation in mice. Neuroscience. 2008; 152(2): 477

[62] Lee KM, Kang BS, Lee HL, Son SJ, Hwang SH, Kim DS, et al. Spinal NF-kB activation induces COX-2 upregulation and contributes to inflammatory pain hypersensitivity. Eur J Neurosci. 2004; 19(12): 3375.

[63] Fujikawa M, Nishitani N, Ibuki T, Kobayashi S, Matsumura $\mathrm{K}$. Sensory stimuli induce nuclear translocation and phosphorylation of nuclear factor kappa B in primary sensory neurons of mice. Neurosci Res. 2011; 71(2): 178.

[64] Serhan CN. Resolution phase of inflammation: novel endogenous anti-inflammatory and proresolving lipid mediators and pathways. Annual review of immunology. 2007; 25: 101.

[65] Park CK, Xu ZZ, Liu T, Lu N, Serhan CN, Ji RR. Resolvin D2 is a potent endogenous inhibitor for transient receptor potential subtype V1/A1, inflammatory pain, and spinal cord synaptic plasticity in mice: distinct roles of resolvin D1, D2, and E1. J Neurosci. 2011; 31(50): 18433

[66] Xu ZZ, Zhang L, Liu T, Park JY, Berta T, Yang R, et al. Resolvins RvE1 and RvD1 attenuate inflammatory pain via central and peripheral actions. Nature medicine. 2010; 16(5): 592

[67] Bang S, Yoo S, Yang TJ, Cho H, Kim YG, Hwang SW, Resolvin. D1 attenuates activation of sensory transient receptor potential channels leading to multiple anti-nociception. $\mathrm{Br}$ J Pharmacol. 2010; 161(3): 707.

[68] Minami T, Nakano H, Kobayashi T, Sugimoto Y, Ushikubi F, Ichikawa A, et al. Characterization of EP receptor subtypes responsible for prostaglandin E2-induced pain responses by use of EP1 and EP3 receptor knockout mice. Br J Pharmacol. 2001; 133(3): 438.

[69] Ueno A, Matsumoto H, Naraba H, Ikeda Y, Ushikubi F, Matsuoka T, et al. Major roles of prostanoid receptors IP and $\mathrm{EP}(3)$ in endotoxin-induced enhancement of pain perception. Biochemical pharmacology. 2001; 62(2): 157.

[70] Murata T, Ushikubi F, Matsuoka T, Hirata M, Yamasaki A, Sugimoto Y, et al. Altered pain perception and inflammatory response in mice lacking prostacyclin receptor. Nature. 1997; 388(6643): 678 